\title{
Long-range-transported bioaerosols captured in snow cover on Mount Tateyama, Japan: impacts of Asian-dust events on airborne bacterial dy- namics relating to ice-nucleation activities
}

Teruya Maki et al.

Correspondence to: Teruya Maki (makiteru@se.kanazawa-u.ac.jp)

The copyright of individual parts of the supplement might differ from the CC BY 4.0 License. 

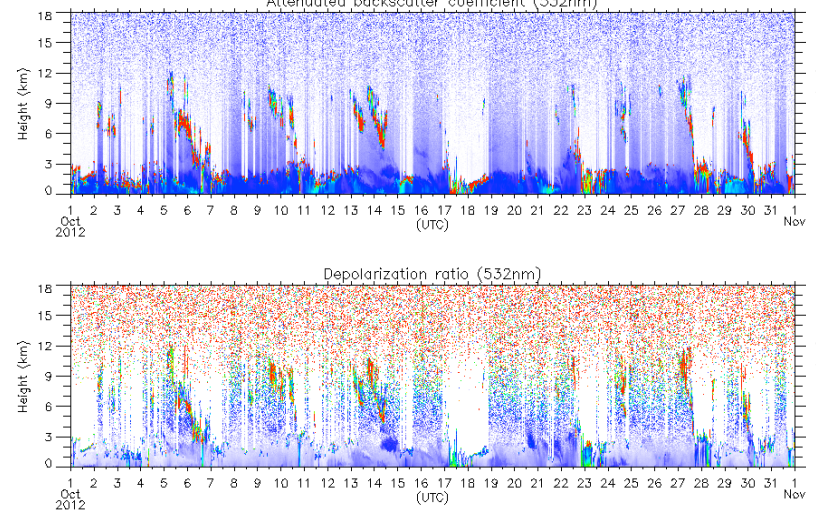

January 2013
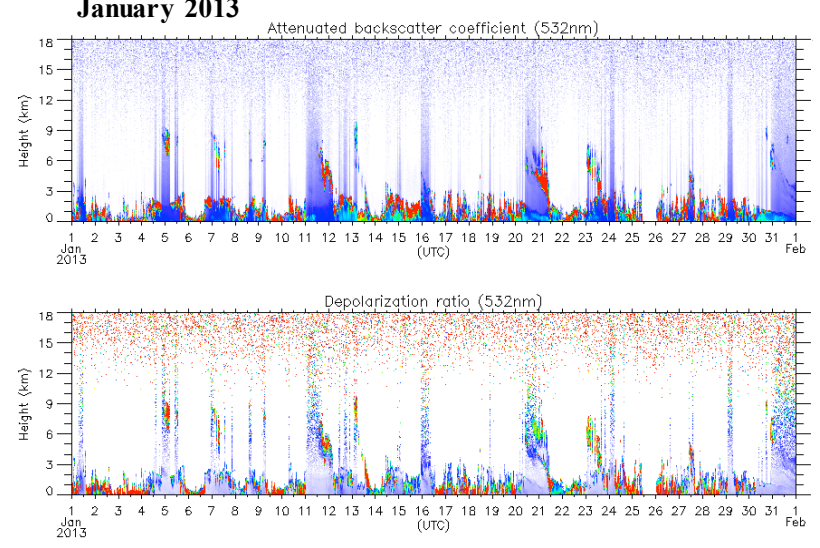

April 2013
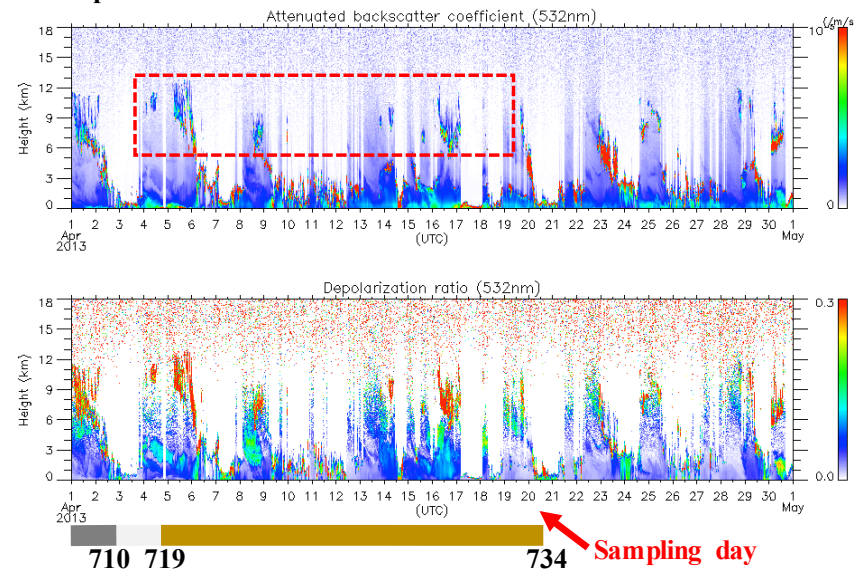

November 2012

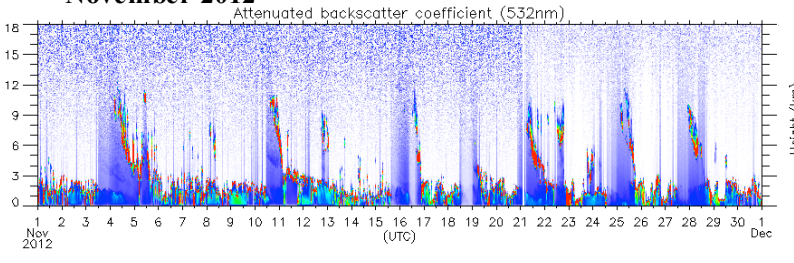

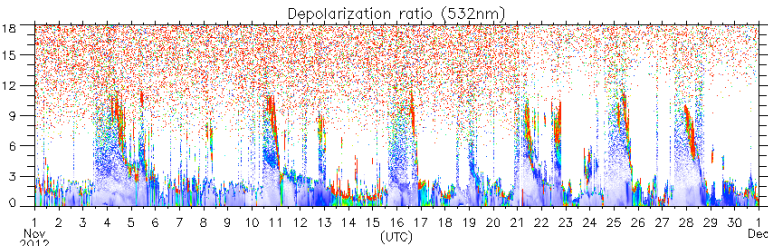

February 2013
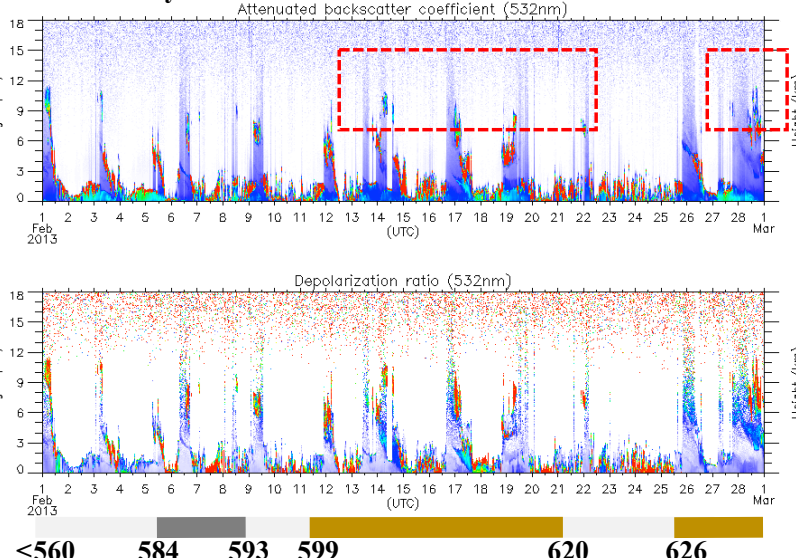

December 2012
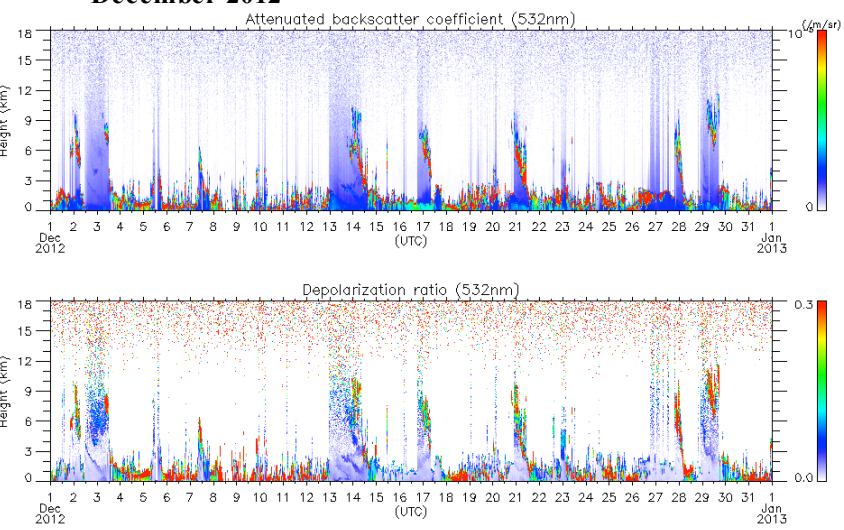

March 2013
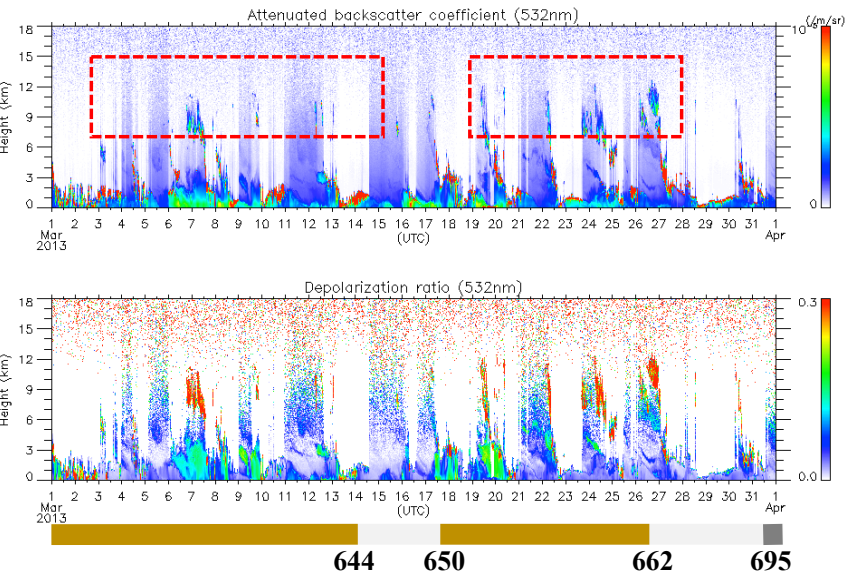

Fig. S1 LIDAR observation of attenuated backscatter coefficient and depolarization ratio in Toyama from October, 2012 to April, 2013. 

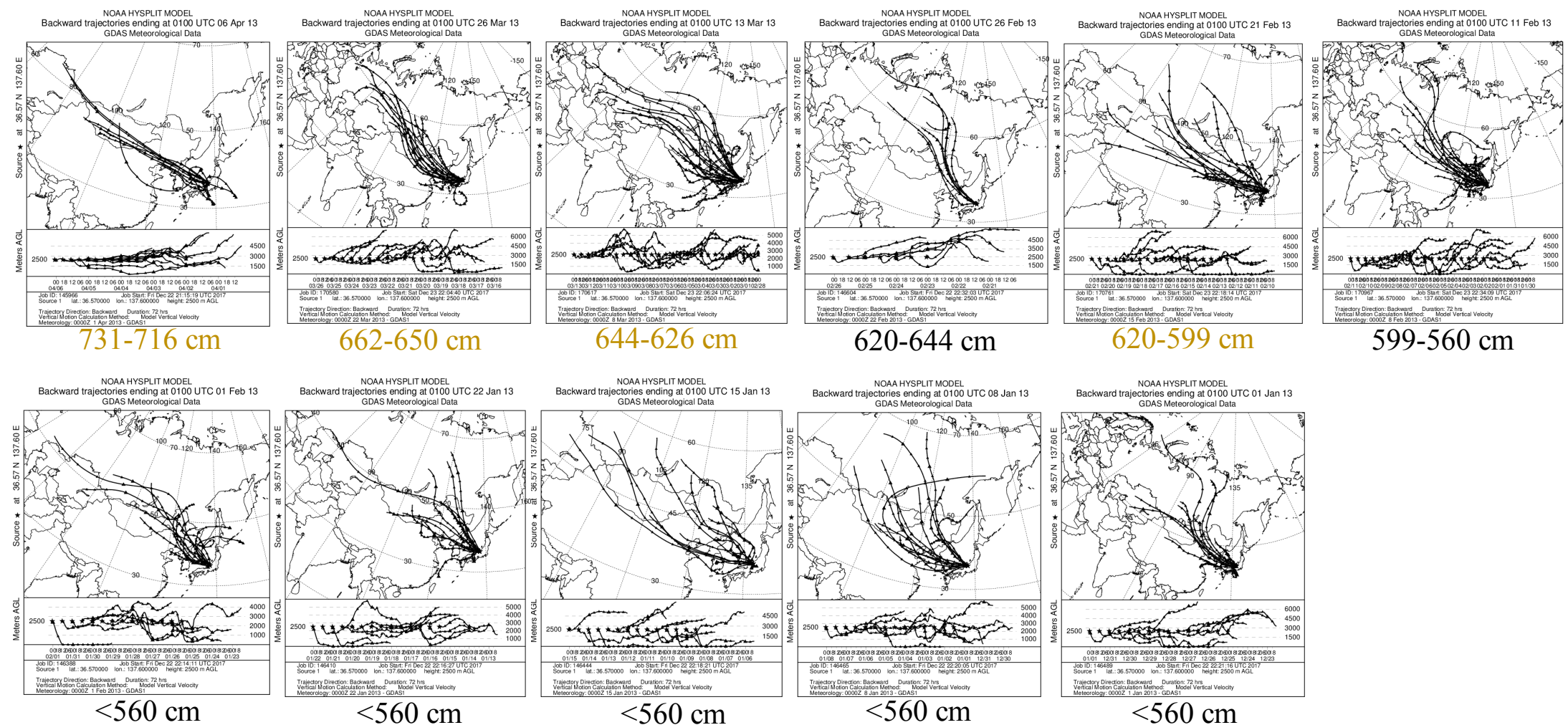

$644-626 \mathrm{~cm}$

$620-644 \mathrm{~cm}$

$620-599 \mathrm{~cm}$

$599-560 \mathrm{~cm}$
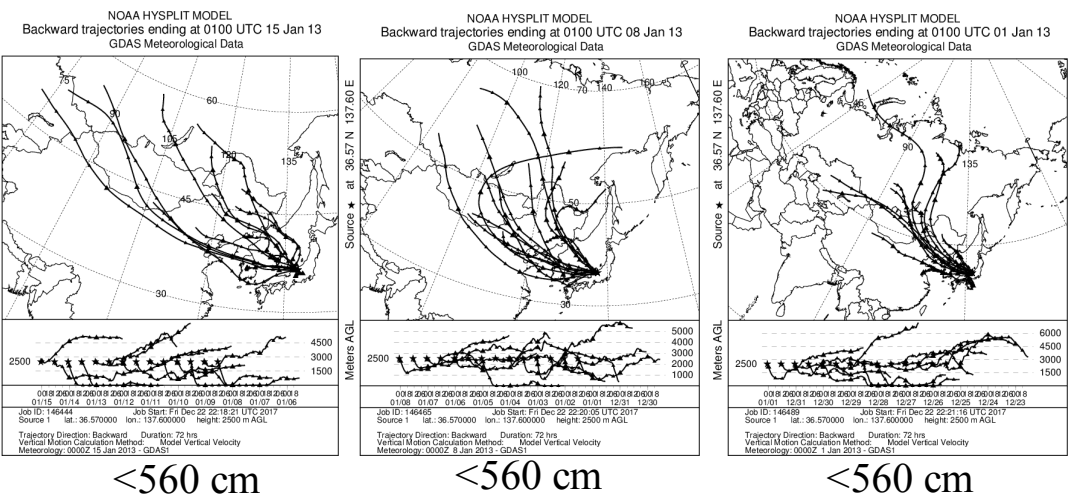

Fig. S2 Three-day back trajectories of aerosols that arrived at 2,500 at Mt. Tateyama during winter and spring in 2013. 


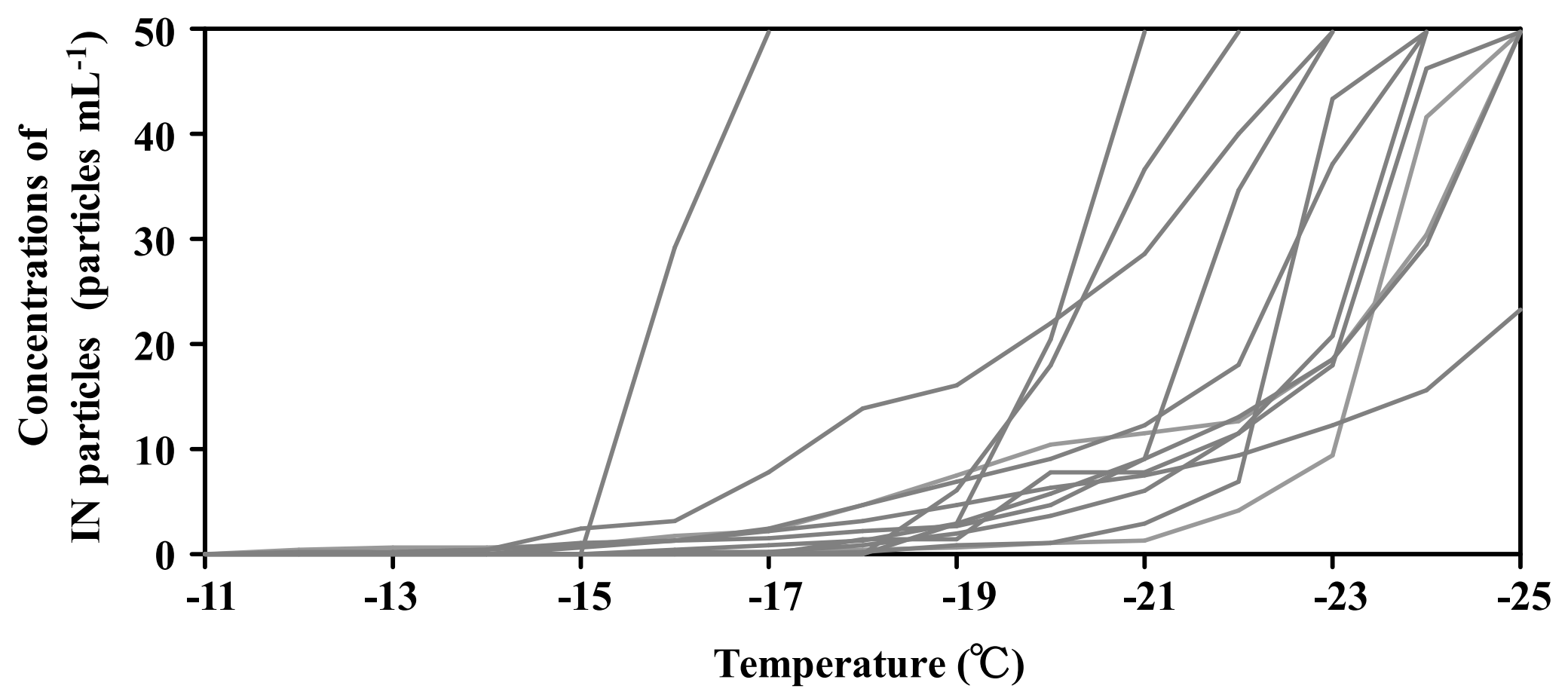

Fig. S3 Variations of IN concentrations in the culture solutions of isolates, which were obtained from the snow samples collected from Murododaira, Mt. Tateyama, in April 2013. 